\title{
CORRESPONDENCE
}

\section{Defence for Chelsea}

SIR - Your correspondent, in summarizing the recommendations of the Committee on Academic Organisation of London University, has failed to comment on an alarming feature of the discussion document. The committee state that their judgements on academic standards in institutions are based on "general reputation" and their own personal opinions. It is on this basis that it is implied that the majority of departments at Chelsea College are not of the standard of the university at all. How else can those who survive the proposed "peer review" be accommodated on a "single site", given the present size of the college?

The University of London is a great, but complex, institution. It faces brutal cuts in funding over an alarmingly short period of time and it was thus wise to have set up the Committee on Academic Organisation under Sir Peter Swinnerton-Dyer to assess the implications of the expected cuts and advise on their implementation with minimal damage to academic standards. But the committee has yielded to the temptation of extrapolating objective financial analysis into arbitrary recommendations based on subjective and highly damaging prejudgements. Instead of setting the scene for cooperative

rationalization and contraction, the document has generated anger and dissention.

The committee had already clearly

established that for years the sub-allocation of the UGC block grant to London by the Court of the University has favoured certain colleges at the expense of others. Inevitably, the high unit-cost colleges, with their favourable facilities and staff ratios, have tended to attract more research grant monies than have the low unit-cost colleges. Nevertheless, and in spite of the conditions under which they have been forced to operate, the under-provided schools have not only become better integrated and more innovative than the giants, but contain many departments of true distinction.

Yet the committee's conclusion is that it is "unthinkable" that the necessary savings should be made where the high costs have been identified. Instead, the worst of the burden is to fall on colleges that, having been starved from the centre, are now judged, a priori, not to be academically excellent - as if, in any case, excellence can ever be ascribed to a college rather than to individual departments.

Chelsea College has survived a succession of externally-engineered crises, and in the face of them has grown from strength to strength. Operating at exceptionally low unit-costs we still have built up departments that are among the biggest and best of their kind in the university, and some of which have a major international reputation. Why then have we been singled out for gratuitous attack? Is it simply and cynically that we are a sitting target, fully-stretched financially and spatially, and big enough if destroyed to spare others their share of the agony?

A simple way to destroy a college is to malign its reputation, so that potential students and benefactors and the various grant-giving bodies shy away. If this is not what the committee consciously set out to do, then the publication of the discussion document represents a sad error of judgment.

The attack on academic standards at Chelsea College not only offends us, it insults boards of studies of the university and its external examiners, jointly charged with maintaining standards in their subjects. They are, by implication, accused of incompetence.

The committee should now retract their scenarios and their gratuitous insults to Chelsea and to the other colleges judged to be "weak", and leave the schools themselves voluntarily to suggest rationalization within objectively defined guidelines. Otherwise, the university should forthrightly reject as incompetent the latter part of the report. H. BAUM

Department of Biochemistry,

Chelsea College, London SW3, UK

\section{Postdocs are OK}

SIR - I object strongly to your comments regarding the future for postdoctoral fellows in the United States (Nature 11 June, p.441).

The 50 per cent increase in postdoctoral grants since 1972 represents an expansion of the equality of opportunity for recent graduates, and the federal policy-makers responsible ought to be applauded, rather than attacked with words like "demeaning employment", "exploited", and "scandal". You confuse an equality of opportunity with an equality of outcome. Sadly, this is a common confusion that muddies the minds of the liberal thinkers of both our peoples, and breeds frustration amongst the unfortunate victims that subscribe to their thought.

The value of postdoctoral study and its "prize" of an academic post remain intact ("88 per cent of the most recently appointed assistant professors in chemistry had done a postdoctoral stint" etc., p.443). For many, this study is preceded by an overkill of classroom exercises and examinations, and followed by endless faculty committee meetings and governmental paperwork, leaving only those precious postdoctoral years where one can devote full time to research, and attempt to achieve the scholastic maturity necessary for undertaking truly independent investigations. (Incidentally, independence is the mark of a "professional", not the social status, health insurance, or salary implied by your comments and the juvenile anecdotes of the disappointed. Anything less denotes hired help, regardless of training, qualification, or special ability.) The statistics of the Grodzins Committee fail to take into account those students of highest ability and fortune who achieve this maturity while earning their degree (all are supposed to) and therefore do not need a postdoctoral period of additional opportunity. For the remaining majority, it stands to reason that an increase in the numbers electing to enter this race for a fixed number of prizes will be followed by an increase in the numbers who do not win. Is that so surprising as to deserve front page coverage? Is it morally offensive? Is it indicative of someone in authority having failed in their responsibility, as you state? I think not. You propose that those who do not win "should be paid a bounty, a kind of retrospective recompense for deprivations". Now that I do find morally of fensive, lying somewhere between race-fixing and squandering public money on a losing proposition, or to be blunt, on losers.

DEXTER B. NORTHROP

University of Wisconsin-Madison, USA

\section{Cox sure?}

SIR - Barry Cox's comments on the British Museum (Natural History) exhibit on Origin of Species (Nature 4 June, p.373) contain an incredible statement which must not pass without challenge. Otherwise, the creationists' claim that evolutionary science is really dogma will have received the imprimatur of your journal. The statement is:

"We [biologists] don't even think that it [the evidence] could support a dramatically different scientific (sic) theory, in the way that earlier observations of the heavens were transformed from being compatible with an Earth-centred Universe to demonstrating a Sun-centred Solar System."'

As a practising biologist, I wish to register my dissent. Surely, Dr Cox got carried away. Does he understand the implications of novel findings in genetics so completely that he can make such a statement with serenity? Is it certain that new data on genome organization and variation will not lead to fundamentally new ideas about the mechanisms of speciation? Have we fully assimilated the lessons of overlapping and interrupted coding sequences, mobile genetic elements, and somatic differentiation by chromosome rearrangements? With all due respect to Dr Cox and the many scientists who believe that the problem of evolution is solved "in principle", let me state my conviction that there is a great deal of aptness in the analogy between Ptolemaic astronomy and our current understanding of evolution.

JAMES A. SHAPIRO

Department of Microbiology,

University of Chicago, Illinois, USA

\section{Fit for what?}

SIR - In his article (Nature 4 June, p.373) on the new Origin of Species exhibition in the British Museum (Natural History), Dr Cox quotes the sound track of a film loop "The Survival of the Fittest is an empty phrase, it is a play on words". This appears to refer to the widespread belief that "survival of the fittest" is a tautology, because our only measure of the fitness of an organism is its ability to survive. This is not so; in the long run survival is a problem for palaeontology, because fossils are our only evidence of what has failed to survive. And in palaeontology, there is a technique which can be used to estimate fitness (in the ordinary dictionary sense). This uses the "paradigm" method developed by Rudwick' for testing functions inferred from structures in fossils. The structure concerned is compared with a paradigm which is the ideal for the performance of that function (due allowance being made for the nature of animal materials). $\mathrm{Paul}^{2}$ has taken this farther, and compared with the appropriate paradigms a series of structures which perform the same functions in different primitive echinoderms. He concluded that, for the functions of protection, feeding and respiration, the echinoderms of the Cambrian and Ordovician were less efficient than their successors. Moreover, this was compatible with the elimination of the unfit by competition (which is "survival of the fittest" in reverse).

Continued on $p .95$ 